\title{
Feeling good in old age: factors explaining health-related quality of life
}

\author{
Manuela Alcañiz ${ }^{1,2^{*}}$ (D) and Aïda Solé-Auró ${ }^{3}$
}

\begin{abstract}
Background: Sustained growth in longevity raises questions as to why some individuals report a good quality of life in older ages, while others seem to suffer more markedly the effects of natural deterioration. Health-related quality of life (HRQL) is mediated by several easily measurable factors, including socio-demographics, morbidity, functional status and lifestyles. This study seeks to further our knowledge of these factors in order to outline a profile of the population at greater risk of poor ageing, and to identify those attributes that might be modified during younger stages of the life course.

Methods: We use nationally representative data for Catalonia (Spain) to explain the HRQL of the population aged 80-plus. Cross-sectional data from 2011 to 2016 were provided by an official face-to-face survey. HRQL was measured using EQ-VAS - the EuroQol-5D visual analogue scale - which summarizes current self-perceived health. Multivariate linear regression was used to identify variables influencing the EQ-VAS score.
\end{abstract}

Results: Sociodemographic factors, including being older, female, poorly educated and belonging to a low social class, were related with poor HRQL at advanced ages. The presence of severe mobility problems, pain/discomfort, and anxiety/ depression were highly correlated to the HRQL of the elderly, while problems of self-care and with usual activities had a weaker association.

Conclusions: Encouraging the young to stay in education, as well as to adopt healthier lifestyles across the lifespan, might ensure better HRQL when individuals reach old age. More multidisciplinary research is required to understand the multifaceted nature of quality of life in the oldest-old population.

Keywords: Oldest-old population, Health-related quality of life, EuroQol-5D, Spain

\section{Background}

Life expectancy today is higher than ever before, with the modal length of life in low-mortality regions approaching 91 years for women and 86 years for men [1]. At the global scale, low- and middle-income countries are recording large declines in mortality at younger ages [2], while in high-income countries the gains in life expectancy are due mainly to the decreasing trends in mortality rates among the elderly [3]. Although in these more advanced economies current life expectancy at older ages reflects current mortality conditions and reaching the fourth age has become a relatively normal ageing phenomenon, exposure to different conditions across the lifespan results in lower

\footnotetext{
* Correspondence: malcaniz@ub.edu

'Riskcenter, Department of Econometrics, Statistics and Applied Economy,

Universitat de Barcelona, Av. Diagonal 690, 08034 Barcelona, Spain

${ }^{2}$ Faculty of Economics and Business, Universitat Oberta de Catalunya, Av.

Tibidabo 39-43, 08035 Barcelona, Spain

Full list of author information is available at the end of the article
}

rates of survival to old age for earlier- than for later-born cohorts [4]. Nevertheless, the 'long-lived' population continues to grow rapidly in many countries thanks to increasing rates of survival at all ages, particularly among the elderly, and past fertility trends [5].

Adding years to the lifespan gives rise to new challenges, as the dynamics of health in older age are both complex and require addressing from a multidisciplinary perspective $[6,7]$. While living a long life in good health is a universal aim, ageing is a multifaceted, long-term process that is not faced with equal success by all individuals [8]. A consideration of only the specific diseases or limitations that might affect an older person would be an overly simplistic approach to take here, given that what is required is an evaluation of their impact on trajectories of health and functioning [9]. Ultimately, it is assessments of the quality of life (QoL) that are indicative of poor or successful ageing processes [10]. 
QoL is neither readily defined nor operationalized given its multidimensional nature [11]. One of its most critical dimensions can be identified as health-related quality of life (HRQL), which is concerned with the effects of health, illness and treatment on QoL, but which excludes cultural, political or societal attributes of life. There is an extensive literature describing different methods for measuring HRQL [12-14], but some authors [15] identify two main types. The first is that of direct elicitation, which includes such methods as time trade-off and rating scales. The time trade-off method involves asking subjects to imagine having to live in a given state of poor health for " $x$ " years, and then to identify the number of years in full health that they consider to be of equal value [16]. For example, if a respondent considers that living for six years in full health is equivalent to being confined to a wheelchair for ten years, the utility that that person assigns to the state of being in a wheelchair can be used to calculate their QoL in that state of health. Alternatively, rating-scale methods, such as visual analogue scales, involve asking subjects to rate their state of health on a scale from 0 to 100, ranging from worst to best health imaginable. The second type of methods for assessing HRQL involves indirect procedures. These use health status instruments such as the Health Utilities Index [17] or the EuroQol [18]. None of these methods requires subjects to self-assign a QoL score; rather, an index is estimated on the basis of their responses to questions about different dimensions of their health, including mobility and pain [19, 20].

This study is conducted in Catalonia, a high-income Spanish region, and focuses on a population that is currently undergoing an accelerated ageing process. According to information released for 1990 by the region's official website, 176,565 individuals were then aged 80 and above, that is, $2.9 \%$ of the whole Catalan population. More recently, in 2016, the size of this oldest-old age group had more than doubled, and today it represents $6.0 \%$ of the overall population [21]. Under an average scenario, demographic projections indicate that this rate is set to reach almost $10.0 \%$ by 2040 . Aside from the challenges this represents for the public pension system [22], from a healthcare perspective this process highlights the need for optimal resource management, along with welldesigned prevention and promotion actions.

Within this demographic context, several crosssectional [23-25] and longitudinal [26, 27] studies examine the correlates of HRQL in older adults, but little is known about the oldest-old population. We aim to fill this research gap by focusing on a twofold objective with regards to the population aged 80 and over. First, we seek to develop a model that can provide a better understanding of the way in which demographic, educational, health and lifestyle variables correlate to
HRQL. Second, we aim to identify those factors frequently linked to poor ageing that can actually be modified in earlier stages of life.

\section{Methods \\ Data}

We conducted a cross-sectional study in Catalonia (Spain), a region with 7.5 million inhabitants, whose capital and largest city is Barcelona. Our microdata are drawn from the Catalan Health Survey (ESCA) [28], which provides extensive information on individuals' health-related behaviour and state of health, in relation to a set of sociodemographic variables. This official survey was first conducted in 1994 and since 2010 it has been repeated on a twice-yearly basis. The sample uses a random complex design, with strata based on age, gender and geographical area [29]. Personal interviews are used to collect the data, and the questionnaires used in each time-period are designed to be comparable.

To obtain a sufficiently large sample size, we used data made available over the last six years (2011 to 2016). Our final sample comprised a randomly selected population of 2264 home-dwellers (1025 males and 1239 females) aged 80 years and above. In $42.6 \%$ of the cases, the interviewer was unable to locate the designated sample individual. However, following the ESCA standard procedure, he/she was provided with a substitute that was identical to the original in terms of their stratification variables. In addition, 567 interviews were conducted through an indirect informant, owing to problems of ill-health or other impediments presented by the selected respondent. The overall final response rate was $100 \%$.

\section{Measures}

EuroQol-5D was used to assess the HRQL of our population of individuals aged 80 and over. This standardized instrument was developed in Europe in 1990 by the EuroQoL Group [18] and has since been widely used. It comprises two parts - an indirect and a direct procedure for assessing HRQL: that is, a descriptive health classifying system (EQ-5D) and a visual analogue scale (EQVAS), respectively. The EQ-5D is a self-report questionnaire that asks respondents to classify their own health according to five dimensions: mobility, self-care, usual activities, pain or discomfort, and anxiety or depression. Since 2011, the ESCA questionnaire has incorporated the five-level Spanish version [30], with five degrees of severity ranging from no problems to extreme impairment [31]. Additionally, the EQ-VAS, a rating-scale method, allows respondents to provide a global assessment of their health status "today", from 0 to 100 . Here, we opted to group the EQ-VAS values into four intervals delimited by quartiles, ranging from worst to best HRQL: i) interval $1: \leq 40$; ii) interval 2 : 41 to 55 ; iii) 
interval 3: 56 to 70; and iv) interval 4: > 70. The EuroQol Group recommends the use of both parts of the instrument for research purposes [32].

We also took into consideration several sociodemographic, health status, and healthcare variables associated with HRQL. The sociodemographic characteristics included gender, age (three groups: 80-84; 85-89; 90plus), level of education (low - less than high school vs. middle/high - upper secondary or tertiary), social class based on the classification proposed by the Spanish Society of Epidemiology [33] (low vs. middle/high social class), and household size (lives alone or lives with other household members). Levels of sensory and physical limitation were included by drawing on several different indicators. Specifically, the severity of sensory impairment was constructed by summing the number of affirmative responses when reporting the presence of limitations in: (i) hearing; (ii) seeing; (iii) speaking; and (iv) writing or reading. The level of functional loss was likewise constructed from affirmative responses indicating: (i) severe limitations in getting out of the house alone; (ii) walking problems that require mobility aids, the help of another person, or a wheelchair; and (iii) other physical movement impairments, such as difficulties in climbing ten steps without help. Chronic morbidity was measured through the number of selfreported chronic conditions, with subjects being asked if they currently have or had had various conditions selected from a list of 32, including hypertension, hypercholesterolemia, diabetes, etc. We also considered the occurrence of falls in the previous 12 months, the need for help to complete activities of daily living (ADLs), and the level of physical activity (from sedentary to highly active). A range of variables has typically been used as indirect controls of health indicators and to help classify individuals into a specific category. As risky health behaviours, we considered the following variables: body mass index (underweight or obese, that is, a BMI of $<18.5$ or $\geq 30$ vs. normal or overweight, that is, a BMI of $\geq 18.5$ or $<30$ ), smoking (current smoker, former smoker or never smoked), and drinking (non-drinker; moderate drinker, that is, drinking less than $280 \mathrm{~g}$ of pure alcohol per week for men, and $170 \mathrm{~g}$ for women; or at-risk drinker, when these limits are exceeded, or alcohol use is over $50 \mathrm{~g}$ in $24 \mathrm{~h}$ at least once a month). These alcohol intake categories were defined according to the classification provided by the Spanish Society of Family and Community Medicine [34]. As for healthcare and the use of medical resources, respondents reported about the number of prescription drugs taken during the previous two days, the number of overnight stays in a hospital within the preceding 12 months, and the number of visits or calls to the emergency department during the same period.

\section{Statistical analysis}

We analysed the descriptive data of the sociodemographic characteristics and health status of Catalan adults aged 80-plus in relation to the EuroQoL instrument. Specifically, we provide the severity distribution for each dimension on the EQ-5D questionnaire, and the individual characteristics according to the quartile interval on the EQ-VAS. Continuous variables are described using means and standard deviations (SD), and categorical variables using percentages (\%). Sampling weights provided by the ESCA are used in the analyses to correct for age and gender deviations between our sample and the Catalan population.

A multivariate linear regression model was fitted using ordinary least squares (OLS), to detect which components affected the EQ-VAS score for HRQL. To this end, we estimated and compared three different regression models. In a first step, Model 1 estimated the effect of the EQ-5D scale measures on the EQ-VAS score to determine their influence. Specifically, we wished to analyse the relationship between the score recorded by the study population on the EQ-VAS and their perception of the degree of severity of each of their limitations included in the EQ-5D. Our objective in so doing was to determine whether there are dimensions or degrees of severity that are more closely associated than others with a decrease in HRQL. In a second step, we omitted the EQ-5D measures, and included all the control variables, so as to identify their effect on the EQ-VAS score (Model 2). We aimed to facilitate identification of the net association between these variables and the assessment of HRQL measured using this scale, which lies at the core of our study. Finally, to determine how the variables included in Model 2 interact with the EQ-5D dimensions, we combined Models 1 and 2 (Model 3).

We tested for heteroscedasticity and multicollinearity in the three sequential models and obtained mainly negative results. Only Model 3 was slightly affected by some correlation between the EQ-5D variables and the rest of the regressors. However, as the latter is a combined model, we decided to maintain all the explanatory variables. The outcomes of the OLS models are presented as coefficients with their respective $p$-values (significance levels at 1, 5 and 10\%). All statistical analyses were conducted with Stata version 13.1.

\section{Results}

\section{Univariate analysis}

Table 1 shows the distribution of individuals according to the reported level of severity on the EQ-5D dimensions. The dimensions most frequently identified by the respondents as severe/extreme problems were limitations related to usual activities (26.2\%) and mobility (24.6\%). Indeed, mobility issues, together with pain/ 
Table 1 Distribution (\%) and 95\% confidence intervals for the EQ-5D dimensions by levels of severity. Individuals aged 80-plus

\begin{tabular}{|c|c|c|c|c|c|c|c|c|c|c|}
\hline \multirow{2}{*}{$\begin{array}{l}\text { EQ-5D } \\
\text { dimensions }\end{array}$} & \multicolumn{10}{|c|}{ Total sample $(N=2264)$} \\
\hline & $\begin{array}{l}\text { No } \\
\text { problems }\end{array}$ & Cl 95\% & $\begin{array}{l}\text { Mild } \\
\text { problems }\end{array}$ & Cl 95\% & $\begin{array}{l}\text { Moderate } \\
\text { problems }\end{array}$ & Cl 95\% & $\begin{array}{l}\text { Severe } \\
\text { problems }\end{array}$ & Cl 95\% & $\begin{array}{l}\text { Extreme } \\
\text { problems }\end{array}$ & Cl 95\% \\
\hline Mobility & 33.9 & $(32.0 ; 35.8)$ & 17.6 & $(16.0 ; 19.2)$ & 23.9 & $(22.1 ; 25.7)$ & 19.8 & $(18.2 ; 21.4)$ & 4.8 & $(3.9 ; 5.7)$ \\
\hline Self-care & 60.4 & $(58.4 ; 62.4)$ & 11.3 & $(10.0 ; 12.6)$ & 10.7 & $(9.4 ; 12.0)$ & 7.3 & $(6.2 ; 8.4)$ & 10.4 & $(9.1 ; 11.7)$ \\
\hline Usual activities & 45.0 & $(43.0 ; 47.0)$ & 14.5 & $(13.0 ; 16.0)$ & 14.3 & $(12.9 ; 15.7)$ & 11.3 & $(10.0 ; 12.6)$ & 14.9 & $(13.4 ; 16.4)$ \\
\hline $\begin{array}{l}\text { Pain/ } \\
\text { discomfort }\end{array}$ & 33.0 & $(31.1 ; 34.9)$ & 16.8 & $(15.3 ; 18.3)$ & 29.2 & $(27.3 ; 31.1)$ & 17.7 & $(16.1 ; 19.3)$ & 3.2 & $(2.5 ; 3.9)$ \\
\hline $\begin{array}{l}\text { Anxiety/ } \\
\text { depression }\end{array}$ & 63.1 & $(61.1 ; 65.1)$ & 15.6 & $(14.1 ; 17.1)$ & 13.6 & $(12.2 ; 15.0)$ & 6.0 & $(5.0 ; 7.0)$ & 1.7 & $(1.2 ; 2.2)$ \\
\hline
\end{tabular}

Source: ESCA 2011-2016

$\mathrm{Cl}$ confidence interval

discomfort, affected about two-thirds of the population to some degree, although only relatively small proportions identified them as extreme problems (4.8 and 3.2\%, respectively). In contrast, roughly two-thirds of individuals reported no limitations as regards self-care and anxiety/depression (60.4 and 63.1\%, respectively).

The study sample, of which $64.4 \%$ were women, presented a mean age of 85.9 years (SD 4.3), with slightly more than half falling in the youngest age group (80-84) (Table 2). The vast majority of respondents had not completed secondary education (86.5\%) and were of low social class $(75.5 \%)$, while almost three quarters $(72.2 \%)$ reported not living alone. As for their health, 32.4\% of the respondents reported sensory problems of some degree; $44.5 \%$ presented a severity level of 2 or 3 in terms of functional loss; and, the average number of chronic diseases reported was $7.2(4.0 \mathrm{SD})$. About a fifth of respondents reported suffering a fall in the previous 12 months, while more than half reported needing help with activities of daily living (ADLs) and being sedentary (with just $35.6 \%$ being slightly active or more). The average number of prescription drugs taken over the previous two days was 4.1 (SD 2.6). In the case of the three risk factors studied, $83.1 \%$ reported a normal/overweight BMI, 78.6\% never smoked, and almost all reported being non-drinkers $(52.7 \%)$ or moderate drinkers (46.6\%). Finally, $17.4 \%$ of the elderly had been hospitalized in the previous year, with an average of 0.7 emergency visits (SD 1.6).

Table 2 also shows the characteristics of the 80-plus population according to their EQ-VAS scores (broken down into four intervals delimited by quartiles). The first interval (those with the lowest HRQL score) comprised the largest proportion of women $(70.3 \%$ vs. $55.3 \%$ in the fourth interval, reporting the highest scores), with the highest average age ( 86.0 vs. 84.5$)$, the largest proportions with a low education level $(92.4 \%$ vs. $79.4 \%)$ and low social class $(80.4 \%$ vs. $66.6 \%)$ and the highest proportion living in a shared household (79.5\% vs. $73.1 \%)$. As expected, the least advantaged group according to the EQ-VAS score reported the worse state of health in relation to all sensory, functioning and health variables, as well as the greatest use of health resources. The differences between intervals were especially notable in relation to reported levels of some sensory loss $(51.7 \%$ in the first interval vs. just $17.1 \%$ in the fourth), the severest level of functional loss (63.2\% vs. 9.7\%), the average number of chronic diseases (9.5 vs. 4.9) and the need for help with ADLs $(87.2 \%$ in the first vs. $20.6 \%$ in the fourth). BMI and lifestyles were healthier in the group with the highest HRQL scores. Differences between the first and fourth intervals were notable in the cases of sedentarism ( $80.3 \%$ versus $37.7 \%)$, being underweight or obese (33.0\% versus $8.9 \%)$, and the proportion of nondrinkers $(65.5 \%$ versus $39.9 \%)$. Likewise, while $28.8 \%$ of the elderly in the first interval had been hospitalized in the previous 12 months, with an average of 1.3 emergency visits, the corresponding figures for those in the fourth interval were $10.4 \%$ and 0.4 . In short, a persistent pattern is evident with conditions improving across the board as we move from the first (lowest EQ-VAS score) to the fourth (highest EQ-VAS score) interval.

\section{Multivariate analysis}

In the multivariate analysis stage, we estimated the linear regression coefficients for the EQ-VAS scores in three sequential models. As expected, the five standardized dimensions of the EQ-5D scale explained a large proportion $(40.0 \%)$ of the variation of the EQ-VAS scores (Model 1, Table 3). We found a strong, significant negative association between severe/extreme problems in all five dimensions and the EQ-VAS scores. The expected value for the dependent variable fell as the severity of the disorder increased. By order of magnitude, advanced stages of mobility issues, pain/discomfort, and anxiety/ depression were associated with the largest falls in the EQ-VAS scores, while limitations as regards self-care and usual activities presented a weaker correlation.

Model 2 provides a different approach, as it excludes the EQ-5D measures, and instead includes as regressors certain socio-demographic, morbidity, functional status 
Table 2 Individual characteristics according to the quartiles of the EQ-VAS score. Individuals aged 80-plus

\begin{tabular}{|c|c|c|c|c|c|c|}
\hline & $\mathrm{N}$ & Total & 11 & 12 & 13 & 14 \\
\hline EQ VAS - Intervals ${ }^{a}$ & 2264 & & $\leq 40$ & $41-55$ & $56-70$ & $>70$ \\
\hline Age in years, mean (SD) & 2264 & $85.9(4.3)$ & $86.0(4.6)$ & $85.4(4.3)$ & $84.6(3.9)$ & $84.5(4.4)$ \\
\hline Age groups & 2264 & & & & & \\
\hline $80-84$ & & 52.0 & 42.8 & 48.8 & 57.5 & 59.9 \\
\hline $85-89$ & & 31.6 & 34.4 & 34.8 & 30.0 & 26.4 \\
\hline $90+$ & & 16.4 & 22.8 & 16.4 & 12.5 & 13.7 \\
\hline Sex & 2264 & & & & & \\
\hline Men & & 35.6 & 29.7 & 30.7 & 38.9 & 44.7 \\
\hline Women & & 64.4 & 70.3 & 69.3 & 61.1 & 55.3 \\
\hline Level of education & 2260 & & & & & \\
\hline Low & & 86.5 & 92.4 & 88.6 & 84.4 & 79.4 \\
\hline Middle or high & & 13.5 & 7.3 & 11.4 & 15.6 & 20.6 \\
\hline Social class & 2221 & & & & & \\
\hline Low & & 75.5 & 80.4 & 77.3 & 75.4 & 66.6 \\
\hline Middle or high & & 24.5 & 19.6 & 22.7 & 24.6 & 33.4 \\
\hline Household size & 2264 & & & & & \\
\hline Living alone & & 27.8 & 20.5 & 31.4 & 32.2 & 26.9 \\
\hline More than one member & & 72.2 & 79.5 & 68.6 & 67.9 & 73.1 \\
\hline Level of sensory loss & 2264 & & & & & \\
\hline 0 & & 67.6 & 48.3 & 65.2 & 77.1 & 82.9 \\
\hline 1 & & 19.7 & 24.6 & 23.8 & 16.2 & 13.2 \\
\hline 2 & & 8.6 & 17.6 & 6.4 & 5.6 & 3.5 \\
\hline 3 & & 2.7 & 6.5 & 2.8 & 0.6 & 0.4 \\
\hline 4 & & 1.4 & 3.0 & 1.8 & 0.5 & 0.0 \\
\hline Level of functional loss & 2264 & & & & & \\
\hline 0 & & 38.4 & 10.6 & 30.1 & 52.1 & 65.8 \\
\hline 1 & & 17.1 & 11.1 & 17.5 & 22.4 & 17.0 \\
\hline 2 & & 14.0 & 15.1 & 19.5 & 12.9 & 7.5 \\
\hline 3 & & 30.5 & 63.2 & 32.9 & 12.6 & 9.7 \\
\hline Number of chronic diseases, mean (SD) & 2264 & $7.2(4.0)$ & $9.5(4.0)$ & $7.7(3.6)$ & $6.3(3.5)$ & $4.9(3.2)$ \\
\hline Falls in the previous 12 months & 2264 & & & & & \\
\hline 0 & & 79.0 & 71.1 & 77.3 & 83.2 & 85.2 \\
\hline$>=1$ & & 21.0 & 28.9 & 22.7 & 16.8 & 14.8 \\
\hline Needs help for ADL & 2264 & & & & & \\
\hline Yes & & 51.5 & 87.2 & 60.3 & 32.7 & 20.6 \\
\hline No & & 48.5 & 12.8 & 39.7 & 67.3 & 79.4 \\
\hline Usual physical activity & 1552 & & & & & \\
\hline Highly active & & 0.2 & 0.0 & 0.0 & 0.3 & 0.6 \\
\hline Moderately active & & 0.7 & 0.3 & 0.7 & 0.8 & 1.1 \\
\hline Slightly active & & 34.7 & 14.1 & 24.5 & 42.0 & 52.9 \\
\hline Minimally active & & 8.1 & 5.2 & 8.9 & 9.4 & 7.8 \\
\hline Sedentary & & 56.3 & 80.3 & 65.9 & 47.5 & 37.7 \\
\hline Number of prescription drugs in the last 2 days, mean (SD) & 2264 & $4.1(2.6)$ & $5.3(2.8)$ & $4.5(2.3)$ & $3.6(2.3)$ & $2.9(2.2)$ \\
\hline
\end{tabular}


Table 2 Individual characteristics according to the quartiles of the EQ-VAS score. Individuals aged 80-plus (Continued)

\begin{tabular}{|c|c|c|c|c|c|c|}
\hline & $\mathrm{N}$ & Total & 11 & 12 & 13 & 14 \\
\hline \multicolumn{7}{|l|}{ Risk Factors } \\
\hline Body mass index & 2264 & & & & & \\
\hline Normal or overweight & & 83.1 & 77.0 & 77.6 & 87.8 & 91.1 \\
\hline Underweight or obesity & & 16.9 & 33.0 & 32.4 & 12.2 & 8.9 \\
\hline Smoking & 1697 & & & & & \\
\hline Current smoker & & 2.8 & 3.2 & 2.4 & 2.3 & 3.4 \\
\hline Former smoker & & 16.6 & 12.2 & 16.7 & 23.1 & 19.8 \\
\hline Never smoked & & 78.6 & 84.5 & 80.9 & 74.5 & 76.8 \\
\hline Drinking & 1697 & & & & & \\
\hline Non-drinker & & 52.7 & 65.5 & 57.0 & 50.8 & 39.9 \\
\hline Moderate drinker & & 46.6 & 34.5 & 42.3 & 48.5 & 58.8 \\
\hline At-risk drinker & & 0.7 & 0.0 & 0.7 & 0.8 & 1.3 \\
\hline Hospitalization in the last 12 months & 2262 & & & & & \\
\hline Yes & & 17.4 & 28.8 & 18.8 & 10.7 & 10.4 \\
\hline No & & 82.6 & 71.2 & 81.2 & 89.3 & 89.6 \\
\hline Number of emergency visits in the last 12 months, mean (SD) & 2257 & $0.7(1.6)$ & $1.3(2.5)$ & $0.7(1.3)$ & $0.5(0.9)$ & $0.4(0.8)$ \\
\hline
\end{tabular}

Source: ESCA 2011-2016

Numbers are percentages (\%) unless otherwise stated. SD: standard deviation. EQ-VAS: EuroQol Visual Analogue Scale. I1, I2, 13 and 14 represent the intervals delimited by the EQ-VAS quartiles

andividuals with EQ-VAS score coinciding with a quartile value are assigned to the lower interval

and lifestyle variables that also contribute to explaining the EQ-VAS score. Being older, female, low educated and belonging to the low social class reduced the expected EQ-VAS score. Individuals presenting some level of sensory impairment showed reductions of around 5 units on our HRQL measure for each additional issue reported. A similar outcome was found for those with chronic conditions ( -1.32 for each clinical condition). Being underweight or obese also had a significant negative association (-2.89). Similarly, individuals taking prescription drugs in the previous two days, or who had been hospitalized or attended emergency units in the preceding twelve months presented lower expected HRQL values. The R-squared coefficient for this model was 0.25 . To complete the analysis, we proposed an additional model (Model 3), which merges Models 1 and 2, allowing us to determine whether the variables in Model 2 interact with the EQ-5D dimensions. This last model presented the highest $\mathrm{R}$-squared value (0.42), suggesting a good explanatory capacity. In the case of the EQ-5D dimensions, we found similar results to those presented above, except in relation to self-care and usual activity limitations whose coefficients for slight problems were no longer significant. Age presented a significant positive coefficient, suggesting that the EQ-5D scale might underestimate the dependent variable when combined with the rest of the regressors. On the other hand, gender, social class, underweight or obesity, the number of prescription drugs taken in the last two days and the number of emergency visits in the last 12 months were no longer significant. This result might suggest that these characteristics provide redundant information when the EQ-5D dimensions are included in the model.

\section{Discussion}

This study has aimed to further our understanding of the ways in which sociodemographic, educational, health and lifestyle variables correlate with the HRQL among community-dwelling individuals aged 80-plus in Catalonia, a region where life expectancy is high and continues to increase. In so doing, we used a rating-scale method, the EQVAS, to measure the HRQL. Our findings confirm the multifaceted nature of HRQL in old age. As expected, the five dimensions of the EQ-5D were found to explain a significant proportion of the variability detected in the responses of the oldest-old about their HRQL. However, the consideration of other individual characteristics proved relevant for better outlining the profile of the population at risk of poor ageing due to bad HRQL. Specifically, our results shed new light on how different social and lifestyle factors correlate with the HRQL of the oldest-old. First, in the population aged 80 -plus, they seem to confirm the positive association between being female and older and having a poor HRQL [35]. But, more interestingly, we detected a persistent pattern whereby other factors typically defined in younger stages of the life course are strongly linked to HRQL in later life. Specifically, middle/high levels of educational attainment and middle/high levels of social class 
Table 3 Estimated linear regression models for the EQ-VAS score. Individuals aged 80-plus

\begin{tabular}{|c|c|c|c|c|c|c|}
\hline \multirow[t]{2}{*}{ Variables } & \multicolumn{2}{|l|}{ Model 1} & \multicolumn{2}{|l|}{ Model 2} & \multicolumn{2}{|l|}{ Model 3} \\
\hline & Coefficients & $p$-value & Coefficients & $p$-value & Coefficients & $p$-value \\
\hline \multicolumn{7}{|l|}{ EQ-5D Dimension } \\
\hline \multicolumn{7}{|l|}{ Mobility problems } \\
\hline No problems & - & & & & - & \\
\hline Slight problems & -5.37 & *** & & & -5.16 & $* * *$ \\
\hline Moderate problems & -8.32 & $* * *$ & & & -8.52 & $* * *$ \\
\hline Severe problems & -10.32 & $* * *$ & & & -10.3 & $* * *$ \\
\hline Extreme Problems & -13.61 & *** & & & -14.04 & $* * *$ \\
\hline \multicolumn{7}{|l|}{ Self-care problems } \\
\hline No problems & - & & & & - & \\
\hline Slight problems & -2.51 & * & & & -2.11 & \\
\hline Moderate problems & -5.10 & $* * *$ & & & -5.07 & $* * *$ \\
\hline Severe problems & -6.81 & $* * *$ & & & -6.31 & $* * *$ \\
\hline Extreme Problems & -6.89 & $* * *$ & & & -6.22 & $* * *$ \\
\hline \multicolumn{7}{|l|}{ Usual activity problems } \\
\hline No problems & - & & & & - & \\
\hline Slight problems & -2.13 & * & & & -1.44 & \\
\hline Moderate problems & -4.30 & $* * *$ & & & -3.24 & $* *$ \\
\hline Severe problems & -5.30 & $* * *$ & & & -3.78 & $* *$ \\
\hline Extreme Problems & -7.82 & $* * *$ & & & -6.24 & ** \\
\hline \multicolumn{7}{|l|}{ Pain/Discomfort } \\
\hline No problems & - & & & & - & \\
\hline Slight problems & -3.35 & $* * *$ & & & -3.04 & $* * *$ \\
\hline Moderate problems & -6.57 & *** & & & -5.64 & $* * *$ \\
\hline Severe problems & -9.27 & $* * *$ & & & -8.36 & $* * *$ \\
\hline Extreme Problems & -15.08 & *** & & & -13.71 & $* * *$ \\
\hline \multicolumn{7}{|l|}{ Anxiety/Depression } \\
\hline No problems & - & & & & - & \\
\hline Slight problems & -5.30 & *** & & & -4.47 & $* * *$ \\
\hline Moderate problems & -6.22 & *** & & & -4.69 & $* * *$ \\
\hline Severe problems & -6.52 & *** & & & -4.16 & $* * *$ \\
\hline Extreme Problems & -12.42 & *** & & & -10.71 & $* * *$ \\
\hline Constant & 72.10 & *** & 83.40 & $* * *$ & 52.73 & $* * *$ \\
\hline Age & & & -0.23 & $* *$ & 0.27 & $* * *$ \\
\hline Female [vs. male] & & & -2.40 & *** & 0.38 & \\
\hline Low education [vs. middle/high] & & & -3.58 & $* * *$ & -2.58 & $* *$ \\
\hline Low social class [vs. middle/high] & & & -2.18 & $* *$ & -1.44 & \\
\hline Sensory impairment (0-4) & & & -5.18 & $* * *$ & -1.97 & $* * *$ \\
\hline Chronic conditions (0-33) & & & -1.32 & $* * *$ & -0.49 & $* * *$ \\
\hline Underweight or obese [vs. normal or overweight] & & & -2.89 & $* * *$ & 0.47 & \\
\hline Number of prescription drugs in the last 2 days & & & -0.67 & $* * *$ & 0.21 & \\
\hline Hospitalization in the last 12 months & & & -3.62 & *** & -2.08 & ** \\
\hline Number of emergency visits in the last 12 months & & & -0.89 & $* * *$ & -0.25 & \\
\hline Sample size (N) & 2264 & & 2212 & & 2212 & \\
\hline R-squared & 0.40 & & 0.25 & & 0.42 & \\
\hline
\end{tabular}

Source: ESCA 2011-2016

*** $p<0.01$; ${ }^{*} p<0.05 ;{ }^{*} p<0.10$. Linear regression models were used to estimate the EQ-VAS scores. EQ-VAS: EuroQol Visual Analogue Scale. The reference categories appear in brackets 
were associated with a better HRQL for individuals aged 80 -plus. These findings are in line with studies conducted in countries with different cultures [25,36,37], pointing to the widespread influence of education and income as social determinants of both physical and mental health at different stages of life and also among members of the oldest-age group. In addition to countless benefits across the lifespan, a higher education is an obvious facilitator of a better occupation-based socioeconomic status and, according to our results, of a better HRQL during old age.

While palliating the physical and mental deterioration caused by a long life remains essential, efforts to increase awareness among the population of the importance of preparing for successful ageing at younger stages in the lifecycle might improve the QoL at very old ages. For example, an active lifestyle could help prevent mobility issues or ADL difficulties in later life. In short, components of both health care and broader social issues may contribute to promote the best ageing trajectories [38].

The findings from our study are of considerable interest as they provide empirical evidence regarding a highly relevant aspect of health for contemporary societies. However, a number of limitations should be noted that might affect our results. First, as the ESCA does not target individuals in nursing homes, our results cannot be generalized to the entire oldest-old population. Indeed, our respondents may well be younger than those living in nursing homes, the latter generally being individuals at a higher risk of morbidity and mortality. According to the Catalan Statistics Institute [39], the institutiondwelling elderly represented about $0.6 \%$ of the Catalan population in 2011, with one in every five individuals aged 90-plus living in a nursing home. Second, the ESCA questionnaire was answered indirectly (owing to impairment of sample unit) in $25 \%$ of cases. Even though sensitive questions are avoided in this indirect questionnaire, some response bias might exist. Third, as our results cover a 6-year period, there could be some concealed trends. However, we were obliged to work with this long period in order to have a large enough sample to guarantee the robustness of the results. Finally, our findings would be clearer if longitudinal datasets had been used, but no panel data for Catalonia - or for Spain - are available.

While we recognize these limitations, the analysis presented here also has some strengths. We should stress that we have analysed a large sample of individuals aged 80-plus. Moreover, the official nature of ESCA ensures the quality of the field work and guarantees a full response rate, thus avoiding the underrepresentation of any age strata. As discussed, few studies to date have examined the determinants of HRQL among the oldestold. Indeed, to the best of our knowledge, this is the first study using Spanish data to analyse the determinants of
HRQL for individuals aged 80-plus. Bearing in mind that Spain leads the European life expectancy (83.0 years at birth -with Switzerland-, and 9.9 years at age 80 in 2015 [40]), furthering our knowledge of its oldest-old population is of undeniable interest.

\section{Conclusions}

The multifaceted nature of QoL in old age highlights the need to implement a more multidisciplinary approach to understanding its complexity. A closer consideration of such domains as psychological and social support needs should provide a better insight as to why one elderly individual feels well despite the natural deterioration associated with ageing while another, in apparently similar conditions, feels unwell.

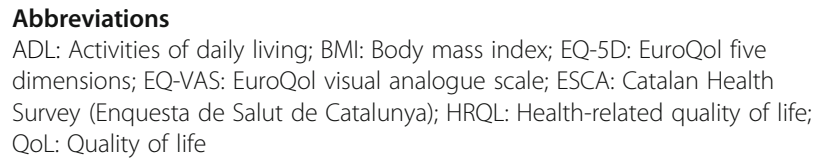
dimensions; EQ-VAS: EuroQol visual analogue scale; ESCA: Catalan Health Survey (Enquesta de Salut de Catalunya); HRQL: Health-related quality of life; QoL: Quality of life

\section{Acknowledgements \\ The authors thank the Catalan Health Department team for sharing data.}

\section{Funding}

This study was supported by the Spanish Ministry of Economy and Competitiveness under Grants ECO2015-66314-R and CSO2016-80484-R. The authors also acknowledge funding from PCIN-2016-005 under the second Joint Programming Initiative "More Years Better Lives", a study that belongs to the multi-country project "Care, Retirement \& Wellbeing of Older People Across Different Welfare Regimes" (CREW).

\section{Availability of data and materials}

The data that support the findings of this study are available from the Catalan Health Department (Generalitat de Catalunya, Spain), but restrictions apply to the availability of these data, which were used under license for the current study, and so are not publicly available. Data are however available from the authors upon reasonable request and with the permission of the Catalan Health Department.

\section{Authors' contributions}

MA conceptualized the study, wrote the first draft and secured authorization to use the survey database. ASA conducted the statistical analysis and its interpretation. Both authors completed the manuscript, provided critical comments and approved the final draft.

\section{Ethics approval and consent to participate}

All procedures were conducted in accordance with the ethical standards of the Generalitat de Catalunya research committee. All the individuals that responded to the survey were informed of the official nature of the Catalan Health Survey, and their obligation to provide the statistical information requested completely and truthfully. Informed consent was obtained from all individual participants included in the study.

\section{Consent for publication}

Not applicable.

\section{Competing interests}

The authors declare that they have no competing interests.

\section{Publisher's Note}

Springer Nature remains neutral with regard to jurisdictional claims in published maps and institutional affiliations. 


\section{Author details}

${ }^{1}$ Riskcenter, Department of Econometrics, Statistics and Applied Economy, Universitat de Barcelona, Av. Diagonal 690, 08034 Barcelona, Spain. ${ }^{2}$ Faculty of Economics and Business, Universitat Oberta de Catalunya, Av. Tibidabo 39-43, 08035 Barcelona, Spain. ${ }^{3}$ DemoSoc Research Group, Department of Political and Social Sciences, Universitat Pompeu Fabra, C/ Ramon Trias Fargas, 25-27, 08005 Barcelona, Spain.

\section{Received: 31 October 2017 Accepted: 8 March 2018 Published online: 13 March 2018}

\section{References}

1. Robine JM, Jagger C. In: Michel J-P, et al., editors. Health expectancies in Oxford Textbook of Geriatric Medicine. 3rd ed; 2017.

2. Bloom DE. 7 billion and counting. Science. 2011;333(6042):562-9.

3. Christensen K, Doblhammer G, Rau R, Vaupel JW. Ageing populations: the challenges ahead. Lancet. 2009;374(9696):1196-208.

4. Solé-Auró A, Crimmins E. The oldest old: health in Europe and the United States. In: Robine JM, Jagger C, Crimmins E, editors. Annual review of gerontology and geriatrics: healthy longevity, a global approach, vol. 33. New York: Springer; 2013. p. 3-33.

5. Mathers CD, Stevens GA, Boerma T, White RA. Causes of international increases in older age life expectancy. Lancet. 2015;385(9967):540-8.

6. Crimmins EM, Beltrán-Sánchez H. Mortality and morbidity trends: is there compression of morbidity? J Gerontol B Psychol Sci Soc Sci. 2011;66(1):75-86

7. Solé-Auró A, Alcañiz M. Are we living longer but less healthy? Trends in mortality and morbidity in Catalonia (Spain), 1994-2011. Eur J Ageing. 2015; 12(1):61-70.

8. WHO. World Health Organization. World report on ageing and health Geneva: WHO Library Cataloguing-in-Publication Data; 2015.

9. Lordos EF, Herrmann FR, Robine JM, Balahoczky M, Giannelli SV, Gold G, et al. Comparative value of medical diagnosis versus physical functioning in predicting the 6-year survival of 1951 hospitalized old patients. Rejuvenation Res. 2008;11(4):829-36.

10. Gabriel Z, Bowling A. Quality of life from the perspectives of older people. Ageing Soc. 2004;24(5):675-91.

11. Halvorsrud L, Kalfoss M. The conceptualization and measurement of quality of life in older adults: a review of empirical studies published during 1994-2006. Eur J Ageing. 2007:4(4):229-46.

12. Guyatt $\mathrm{GH}$, Feeny $\mathrm{DH}$, Patrick DL. Measuring health-related quality-of-life. Ann Intern Med. 1993;118(8):622-9.

13. Hawthorne G, Richardson J, Osborne R. The assessment of quality of life (AQoL) instrument: a psychometric measure of health-related quality of life. Qual Life Res. 1999:8(3):209-24.

14. Hays RD, Morales LS. The RAND-36 measure of health-related quality of life Ann Med. 2001:33(5):350-7.

15. Tengs TO, Wallace A. One thousand health-related quality-of-life estimates. Med Care. 2000;38(6):583-637.

16. Devlin N, Tsuchiya A, Buckingham K, Tilling C. A uniform time trade off method for states better and worse than dead: feasibility study of the 'lead time' approach. Health Econ. 2011;20(3):348-61.

17. Feeny D, Furlong W, Boyle M, Torrance GW. Multi-attribute health status classification systems: health utilities index. PharmacoEconomics. 1995;7:490-502.

18. EuroQoL Group. EuroQoL - a new facility for the measurement of healthrelated quality of life. Health Policy. 1990;16(3):199-208.

19. Torrance GW, Furlong W, Feeny D, Boyle M. Multi-attribute preference functions: health utilities index. PharmacoEconomics. 1995;7:503-20.

20. Badia X, Roset M, Montserrat S, Herdman M, Segura A. La versión española del EuroQol: descripción y aplicaciones. Med Clin. 1999:112(1):79-86.

21. Catalan Statistics Institute, Generalitat de Catalunya. Oficial Statistics Website of Catalonia, Population, 2017. Retrieved from: https://www.idescat.cat/ tema/pobla?lang=en. Accessed 1 Aug 2017

22. Díaz-Giménez J, Díaz-Saavedra J. Delaying retirement in Spain. Rev Econ Dyn. 2009;12(1):147-67.

23. Mulasso A, Roppolo M, Rabaglietti E. The role of individual characteristics and physical frailty on health related quality of life (HROOL): a cross sectional study of Italian community-dwelling older adults. Arch Gerontol Geriatr. 2014:59(3):542-8.

24. Shin KR, Byeon YS, Kang Y, Oak J. A study on physical symptom, activity of daily living, and health-related quality of life (HRQoL) in the communitydwelling older adults. J Korean Acad Nurs. 2008;38(3):437-44.
25. Tajvar M, Arab M, Montarezi A. Determinants of health-related quality of life in elderly in Tehran, Iran. BMC Public Health. 2008:8:323.

26. Roehr S, Luck T, Pabst A, Bickel H, König HH, Lühmann D, et al. Subjective cognitive decline is longitudinally associated with lower health-related quality of life. Int Psychogeriatr. 2017;29(12):1939-50.

27. Eisele M, Kaduszkiewicz H, König HH, Lange C, Wiese B, Prokein J, et al. Determinants of health-related quality of life in older primary care patients: results of the longitudinal observational AgeCoDe study. Br J Gen Pract. 2015;65(640):E716-23.

28. Catalan Health Department, Generalitat de Catalunya (2017) Enquesta de Salut de Catalunya (ESCA). Retrieved from: http://salutweb.gencat.cat/ca/el departament/estadistiques_sanitaries/enquestes/esca/. Accessed 18 June 2017.

29. Alcañiz $M$, Mompart $A$, Guillén $M$, Medina A, Aragay JM, Brugulat $P$, Tresserras R. New design of the health survey of Catalonia (Spain, 2010-2014): a step forward in health planning and evaluation. Gac Sanit. 2014:28:338-40. (in Spanish)

30. García-Gordillo MA, Adsuar JC, Olivares PR. Normative values of EQ-5D-5L: in a Spanish representative population sample from Spanish health survey. Qual Life Res. 2016;25(5):1313-21.

31. Herdman M, Gudex C, Lloyd A, Janssen M, Kind P, et al. Development and preliminary testing of the new five-level version of EQ-5D (EQ-5D-5L). Qual Life Res. 2011:20(10):1727-36.

32. EuroQol Group. EQ-5D-5L user guide. Basic information on how to use the EQ-5D-5L instrument. Rotterdam: EuroQol Research Foundation; 2015. Retrieved from: https://euroqol.org/wp-content/uploads/2016/09/EQ-5D-5L_ UserGuide 2015.pdf. Accessed 3 July 2017

33. Regidor E. The Goldthorpe Social Class Classification: reference framework for a proposal for the measurement of social class by the Working Group of the Spanish Society of Epidemiology. Revista Española de Salud Pública. 2001;75(1):13-22.

34. Robledo T, Córdoba R. Cómo actuar ante el consumo de alcohol: guía de referencia para profesionales de atención primaria [electronic resource]. Barcelona: Sociedad Española de Medicina de Familia y Comunitaria (SEMFYC); 2007. http://www.pnsd.msssi.gob.es/profesionales/publicaciones/ catalogo/bibliotecaDigital/publicaciones/pdf/AlcoholAtencionPrimaria.pdf. Accessed 15 July 2017

35. Rendas-Baum R, White MK, Kosinski M, Vietri J, Bjorner JB. A cross-national comparison of the effect of age and gender on health-related quality of life (HRQL). Value Health. 2016:19(7):A471.

36. Allen J, Balfour R, Bell R, Marmot M. Social determinants of mental health. Int Rev Psychiatry. 2014;26(4):392-407.

37. Braveman $P$, Gottlieb $L$. The social determinants of health: it's time to consider the causes of the causes. Public Health Rep. 2014;129(Suppl 2):19-31.

38. Arpino B, Solé-Auró A. Education inequalities in health among older European men and women: the role of active aging. J Aging Health. 2017. Epub ahead of print.

39. Catalan Statistics Institute, Generalitat de Catalunya. La població resident en establiments collectius 2011. Dossiers Idescat, 2013, 16. Retrieved from: http:// www.idescat.cat/cat/idescat/publicacions/cataleg/pdfdocs/dossier16.pdf. Accessed 6 Aug 2017.

40. Eurostat (2017). Life expectancy by age and sex. Retrieved from: http://appsso. eurostat.ec.europa.eu/nui/show.do?dataset=demo_mlexpec\&lang=en Accessed 20 Feb 2018

\section{Submit your next manuscript to BioMed Central and we will help you at every step:}

- We accept pre-submission inquiries

- Our selector tool helps you to find the most relevant journal

- We provide round the clock customer support

- Convenient online submission

- Thorough peer review

- Inclusion in PubMed and all major indexing services

- Maximum visibility for your research

Submit your manuscript at www.biomedcentral.com/submit 